Discussion Paper No. 1041

\title{
REGIONAL SUBSIDIES \\ AND \\ INTERREGIONAL LABOR MOVEMENT
}

\author{
Daisuke Matsuzaki \\ Yoshiyasu Ono
}

September 2018

The Institute of Social and Economic Research

Osaka University

6-1 Mihogaoka, Ibaraki, Osaka 567-0047, Japan 


\title{
Regional subsidies and interregional labor movement
}

\author{
by \\ Daisuke Matsuzaki ${ }^{\dagger}$ and Yoshiyasu Ono
}

\begin{abstract}
When a government considers a subsidy for an underdeveloped region, it has several options: the subsidies can be for land, wages, employment, or production. While land subsidy is a lump-sum transfer, the others are meant to promote local production or worker immigration. Under full employment, replacing the lump-sum subsidy with the other subsidies benefit (harm) the recipient region if it specializes in labor-intensive (land-intensive) activities. If unemployment prevails in both the recipient and non-recipient regions, production and employment subsidies benefit, but a wage subsidy harms, the recipient region. We also analyze asymmetric cases where one region attains full employment while the other region remains underemployed.
\end{abstract}

JEL classification: F22, H71, R51

Keywords: transfer, subsidies, unemployment, wage rigidity.

* The authors wish to thank Ken-ichi Hashimoto, Shinsuke Ikeda, Tadashi Morita, Takayuki Ogawa, Yoshitomo Ogawa, and seminar participants at Yamaguchi and Osaka Universities for their valuable comments. This work was financially supported by the JSPS KAKENHI Grants (JP15H05728, JP15K13016, and JP16K03664), and the program of the Joint Usage/Research Center for "Behavioral Economics" at ISER, Osaka University. The authors are solely responsible for any errors.

${ }^{\dagger}$ Faculty of Economics, Toyo University, 5-20-28 Hakusan, Bunkyo, Tokyo 112-8606, JAPAN. E-mail: matsuzaki@toyo.jp

Institute of Social and Economic Research, Osaka University, 6-1, Mihogaoka, Ibaraki, Osaka 567-0047, JAPAN. E-mail: ono@iser.osaka-u.ac.jp 


\section{Introduction}

When a government offers a subsidy to a region, it often makes a lump-sum transfer. While this is purely a redistribution, some types of subsidies directly promote employment and stimulate local economic activity. Such subsidies may be particularly important if the recipient region is underemployed. In this paper, we examine the welfare effects of replacing lump-sum transfers by these stimulation subsidies on the recipient and non-recipient regions. For doing so, we adopt a two-region two-factor two-commodity model in which the non-recipient region produces both commodities, but the recipient region produces only one commodity because it is less developed. Each region may achieve full employment or face unemployment, and workers migrate between the two regions in pursuit of higher (expected) labor income. Thus, the welfare of each region is affected by subsidies through changes in terms of trade, interregional migration, and local employment.

Various situations arise in which a government has to offer subsidies. Offering a location for "Not in My Back Yard" (NIMBY) facilities, such as military bases and nuclear power plants, is an example. This often provokes opposition from local communities and their vicinities, and the government has to offer subsidies as compensation (for e.g., see Frey et al., 1996). A typical example in Japan is Okinawa, where most of the US military bases in Japan are located. The Japanese government compensates the land owners in Okinawa by providing them with a land subsidy. Another example is the areas where nuclear power plants or waste repositories are located, with the government offering various subsidies to them. These areas are typically less developed, specializing in the primary industry such as agriculture and fishery, or tourism. The various subsidies include a lump-sum subsidy and subsidies for promoting economic activities. The aim of the present analysis is to compare the welfare effects of these subsidies. 
The regulations for NIMBY facilities have been examined in the literature; for example, see Markusen et al. (1995), Levinson (1999), and Saveyn (2012). These studies examine the effects of pollution taxes and environmental regulation on the location of a NIMBY facility. Some studies examine the compensational schemes for locating a NIMBY facility along with asymmetric information on the damages caused by the facility. For example, Feinerman et al. (2004) consider a two-city model to investigate the lobbying activities of land owners affected by government decisions on the location of facilities. Besfamille and Lozachmeur (2010) adopt a mechanism-design approach to examine the optimal interregional compensation scheme for the host and other regions with full and asymmetric information. While these studies focus on the location choice of NIMBY facilities, this paper considers the case of predetermined recipient regions and total subsidy payments, and compares the welfare effects of various subsidies between the recipient and non-recipient regions.

The regional subsidies' welfare effects in case of interregional migration are also analyzed in the literature of equalization subsidies; for example, Flatters et al. (1974), Boadway and Flatters (1982), and Wildasin (1986). These studies focus on the negative externalities effect of congestion on local public goods, and explore the migration subsidy resulting in optimal interregional allocation of households. Albouy (2012) extends Boadway and Flatters' model (1982) by introducing household income heterogeneity. These studies ignore unemployment, whereas we examine the welfare effects of replacing direct transfers with various subsidies promoting local employment and production on the recipient and non-recipient regions both with and without unemployment.

The local unemployment and interregional migration combination was first modelled by Harris and Todaro (1970). They assumed an economy with a rural area and an urban 
area, where both areas specialize in different commodities, the rural area achieving full employment whereas the urban area facing unemployment due to wage rigidity. In this setting, they found that urban job creation leads to higher urban unemployment (the Todaro Paradox); they also analyzed the effects of urban employment subsidy and immigration restriction on social welfare. Since then, several studies have considered this issue; for example, Bhagwati and Srinivasan (1974), Corden and Findlay (1975), Batra and Naqvi (1987), Nakagome (1989), Raimandos (1993), Brueckner and Zenou (1999), Ortega (2000), Brueckner and Kim (2001), Sato (2004), Choi and Yu (2010), and Zenou (2011). These studies extended the Harris-Torado model by introducing such factors as perfect or imperfect capital mobility, labor market monopsony, land market, and some microeconomic foundations on wage rigidity, for example, efficiency wage and search matching, and explored the validity of the Harris-Todaro model policy implications.

Our analysis differs from the Harris-Todaro model literature in the following three aspects. First, that study focused on social welfare, but we consider local development and regional welfare distribution. Second, we consider both urban and rural unemployment, because rural unemployment is often more serious than, if not as serious as, urban unemployment in Japan. We consider all unemployment and full employment combinations in the two regions. Third, rather than considering perfect specialization in both regions, we assume that the rural region produces only one commodity whereas the non-recipient region produces two commodities; the Heckscher-Ohlin mechanism works in this setting. Furthermore, we find that replacing a lump-sum subsidy with economic activity-stimulating subsidies creates the employment expansion effect and the terms of trade effect in one or both regions, depending on the employment situations of the two regions, and yields different welfare effects. 


\section{The model}

Our model economy has two regions, $\mathrm{W}$ and $\mathrm{E}$, and two commodities, 1 and 2 . While region $\mathrm{W}$ produces both commodities, region $\mathrm{E}$ produces only commodity 1 owing to lack of technology. The government offers a lump-sum subsidy amounting to $S_{r}$ to the land owners in region $\mathrm{E}$. The land of region $j(j=\mathrm{E}, \mathrm{W})$ is assumed to be uniformly owned by all native households of the region. Now, the government considers replacing the lump-sum subsidy with the following stimulative subsidies: production subsidy $\epsilon$, employment subsidy $z$, and wage subsidy $s_{w}$. These subsidies affect production, employment, and migration, and vary labor income. All households freely move between the two regions in pursuit of higher wages, but they retain land ownership in their native region.

The population of households born in region $j$, called household $j$ in this study, is $L_{o}^{j}$, whereas the present population of the households living in region $j$ is $L_{n}^{j}(j=\mathrm{E}, \mathrm{W})$, These populations satisfy

$$
L=L_{o}^{E}+L_{o}^{W}=L_{n}^{E}+L_{n}^{W}
$$

where $L$ is the total population, which is constant. For simplicity, we assume that each region initially has no immigrants, and hence

$$
L_{o}^{j}=L_{n}^{j} \text { for } j=E, W
$$

Furthermore, all households have the same utility function

$$
u^{j}=\widehat{u}\left(c_{1}^{j}, c_{2}^{j}\right) \text { for } j=E, W
$$


where $c_{i}^{j}(i=1,2 ; j=E, W)$ is household $j$ 's consumption of commodity $i$. Assuming the utility function to be homothetic, we have

$$
p_{1}(\omega) c_{1}^{j}=\varphi(\omega) Y^{j}, \quad p_{2}(\omega) c_{2}^{j}=(1-\varphi(\omega)) Y^{j}
$$

where $p_{i}(\omega)$ is the price of commodity $i$ measured in terms of the composite of the two commodities, $\omega$ is the relative price of commodity 2 in terms of commodity $1, Y^{j}$ is household $j$ 's disposable income, and $\varphi(\omega)$ is the ratio of consumption expenditure on commodity 1 , which satisfies

$$
0<\varphi(\omega)<1, \quad \varphi^{\prime}(\omega)>0
$$

Because the utility function is homothetic, the value of $\hat{u}\left(c_{1}^{j}, c_{2}^{j}\right)$, into which the optimal levels of $c_{1}^{j}$ and $c_{2}^{j}$ given in (3) are substituted, is independent of the relative price $\omega$. Thus,

$$
\hat{u}\left(\frac{\varphi(\omega)}{p_{1}(\omega)} Y^{j}, \frac{1-\varphi(\omega)}{p_{2}(\omega)} Y^{j}\right)=\phi\left(Y^{j}\right) \hat{u}\left(\frac{\varphi(\omega)}{p_{1}(\omega)}, \frac{1-\varphi(\omega)}{p_{2}(\omega)}\right) \equiv u\left(Y^{j}\right)
$$

where $\hat{u}(.,$.$) satisfies$

$$
\frac{d \widehat{u}\left(\frac{\varphi(\omega)}{p_{1}(\omega)^{\prime}} \frac{1-\varphi(\omega)}{p_{2}(\omega)}\right)}{d \omega}=\hat{u}_{1} \frac{d\left(\frac{\varphi(\omega)}{p_{1}(\omega)}\right)}{d \omega}+\hat{u}_{2} \frac{d\left(\frac{1-\varphi(\omega)}{p_{2}(\omega)}\right)}{d \omega}=0 .
$$

Because $\hat{u}_{2} / \hat{u}_{1}=\omega=p_{2}(\omega) / p_{1}(\omega)$ under rational household behavior, the above equation yields

$$
p_{1}^{\prime}(\omega)=-\frac{(1-\varphi(\omega)) p_{1}}{\omega}<0, \quad p_{2}^{\prime}(\omega)=\frac{\varphi(\omega) p_{2}}{\omega}=\varphi(\omega) p_{1}>0
$$

The production function of sector $i(i=1,2)$ displays constant returns to scale with respect to two factors, land $K_{i}$ and labor $L_{i}$, and hence is represented by 


$$
f_{i}\left(k_{i}\right) L_{i} \text { where } f_{i}^{\prime}(\cdot)>0, f_{i}^{\prime \prime}(\cdot)<0, \quad k_{i}=K_{i} / L_{i}
$$

Because the government offers no subsidy to region W, the two sectors' profit maximization behavior yields

$$
\begin{gathered}
r^{W}=p_{1}(\omega) f_{1}^{\prime}=p_{2}(\omega) f_{2}^{\prime}, \\
w^{W}=p_{1}(\omega)\left[f_{1}-f_{1}^{\prime} k_{1}\right]=p_{2}(\omega)\left[f_{2}-f_{2}^{\prime} k_{2}\right],
\end{gathered}
$$

where $r^{j}$ and $w^{j}$ are respectively the land rental rate and wage level in region $j$. From (6) and (8), we derive

$$
\begin{gathered}
r^{W}=r^{W}(\omega), \quad r^{W^{\prime}}(\omega)=\frac{p_{2}(\omega) f_{2}-(1-\varphi) r_{\left(k_{2}-k_{1}\right)}}{\omega\left(k_{2}-k_{1}\right)} \\
w^{W}=w^{W}(\omega), \quad w^{W^{\prime}}(\omega)=-\frac{p_{2}(\omega) f_{2} k_{1}+(1-\varphi) w^{W}\left(k_{2}-k_{1}\right)}{\omega\left(k_{2}-k_{1}\right)} \\
k_{1}=k_{1}(\omega), \quad k_{1}^{\prime}(\omega)=\frac{f_{2}}{\left(k_{2}-k_{1}\right) f_{1}^{\prime \prime}}, \\
k_{2}=k_{2}(\omega), \quad k_{2}^{\prime}(\omega)=\frac{f_{1}}{\left(k_{2}-k_{1}\right) p^{2} f_{2}^{\prime \prime}}
\end{gathered}
$$

Region $\mathrm{E}$ has only sector 1 , and the government offers production subsidy $\epsilon$ and employment subsidy $z$ to the firms in this region. Therefore, the optimal firm behavior yields

$$
\begin{gathered}
r^{E}=(1+\epsilon) p_{1}(\omega) f_{1}^{\prime}\left(k_{1}^{E}\right), \\
w^{E}-z=(1+\epsilon) p_{1}(\omega)\left[f_{1}\left(k_{1}^{E}\right)-f_{1}^{\prime}\left(k_{1}^{E}\right) k_{1}^{E}\right],
\end{gathered}
$$

where $k_{1}^{E}$ is the land-labor input ratio in region E. The government also offers wage subsidy $S_{w}$ and land subsidy amounting to $S_{r}$. These are financed by lump-sum taxes, whose total value is $T$, imposed equally on all households in the two regions. The government's budget equation then becomes 


$$
\left[z+s_{w}+\epsilon f_{1}\left(k_{1}^{E}\right)\right] \gamma^{E} L_{n}^{E}=T-S_{r}
$$

where $\gamma^{j}$ is the employment rate in region $j$. Note that because $S_{r}$ is a lump-sum subsidy, the present analysis is valid also where a general lump-sum subsidy, rather than a land subsidy, is paid to household $\mathrm{E}$.

With perfect labor mobility between the two regions, household $j$ 's disposable income, $Y^{j}(j=E, W)$, satisfies

$$
\begin{gathered}
Y^{E}=\left(s_{w}+w^{E}\right) \gamma^{E}+\frac{s_{r}+r^{E} K^{E}}{L_{o}^{E}}-\frac{T}{L}=w^{W} \gamma^{W}+\frac{S_{r}+r^{E} K^{E}}{L_{o}^{E}}-\frac{T}{L}, \\
Y^{W}=\left(s_{w}+w^{E}\right) \gamma^{E}+\frac{r^{W} K^{W}}{L_{o}^{W}}-\frac{T}{L}=w^{W} \gamma^{W}+\frac{r^{W} K^{W}}{L_{o}^{W}}-\frac{T}{L},
\end{gathered}
$$

where the second and third expressions of each equation show respectively the expected income when the household lives in region $\mathrm{E}$, and that when the household lives in region W. From (12),

$$
\left(s_{w}+w^{E}\right) \gamma^{E}=w^{W} \gamma^{W}
$$

where, from (8), $w^{W}$ is a function of $\omega$, and from (10), $w^{E}$ is a function of $\omega, k_{1}^{E}, z$, and $\epsilon$. The factor markets in region $\mathrm{W}$ satisfy

$$
k_{1} L_{1}+k_{2} L_{2}=K^{W}, L_{1}+L_{2}=\gamma^{W} L_{n}^{W},
$$

where $K^{j}$ is the land endowment of region $j$. Thus, we obtain

$$
L_{1}=\frac{k_{2} \gamma^{W}\left(L-L_{n}^{E}\right)-K^{W}}{k_{2}-k_{1}}, \quad L_{2}=\frac{K^{W}-k_{1} \gamma^{W}\left(L-L_{n}^{E}\right)}{k_{2}-k_{1}} .
$$

Since region E includes only sector 1, we have

$$
\gamma^{E} L_{n}^{E} k_{1}^{E}=K^{E}
$$


From (3) and (16), we obtain the market equilibrium conditions for commodities 1 and 2 as follows:

$$
\begin{gathered}
p_{1} f_{1} L_{1}+p_{1} f_{1}\left(k_{1}^{E}\right) \frac{K^{E}}{k_{1}^{E}}=\varphi(\omega)\left(Y^{E} L_{o}^{E}+Y^{W} L_{o}^{W}\right) \\
p_{2} f_{2} L_{2}=(1-\varphi(\omega))\left(Y^{E} L_{o}^{E}+Y^{W} L_{o}^{W}\right) .
\end{gathered}
$$

These yield

$$
\frac{f_{1} L_{1}+f_{1}\left(k_{1}^{E}\right) \frac{K^{E}}{k_{1}^{E}}}{f_{2} L_{2}}-\delta(\omega)=0
$$

where $\delta(\omega) \equiv \frac{\omega \varphi(\omega)}{1-\varphi(\omega)}, \quad \delta(\omega)>0, \quad \delta^{\prime}(\omega)>0$,

and we derive the properties of $\delta(\omega)$ from (4).

\section{Policy analysis}

Having established the model, we next analyze the welfare effects of subsidy replacement. The government originally pays land subsidy $S_{r}$ to household E, and then replaces it with the wage, employment, or production subsidy $\left(s_{w}, z\right.$ or $\left.\epsilon\right)$; this urges workers to move into the region and firms to increase local production.

We assume that the subsidies initially satisfy

$$
s_{w}=0, \quad z=0, \varepsilon=0,
$$

and analyze the welfare effects of the replacement policies in the following four situations: (i) full employment in both regions, (ii) unemployment in both regions, (iii) unemployment in region $\mathrm{W}$ and full employment in region $\mathrm{E}$, and (iv) full employment in region $\mathrm{W}$ and unemployment in region E. For simplicity, we assume that unemployment is the result of 
wage rigidity. Noting that $w^{W}=w^{W}(\omega)$, from (9), the endogenous and exogenous variables in each case are

$$
\begin{aligned}
& \text { (i) } w^{E} \text { and } \omega \text {, while } \gamma^{E}=1, \gamma^{W}=1 \text {; } \\
& \text { (ii) } \gamma^{E}(<1) \text { and } \gamma^{W}(<1) \text {, while } w^{E}=\bar{w}^{E}, w^{W}(\omega)=\bar{w}^{W} \text {; } \\
& \text { (iii) } w^{E} \text { and } \gamma^{W}(<1) \text {, while } \gamma^{E}=1, w^{W}(\omega)=\bar{w}^{W} \text {; } \\
& \text { (iv) } \gamma^{E}(<1) \text { and } \omega \text {, while } w^{E}=\bar{w}^{E}, \gamma^{W}=1
\end{aligned}
$$

While the three subsidies raise the labor income, their effects on employment significantly differ. Employment and production subsidies, $z$ and $\varepsilon$, respectively, urge local firms to produce more and thereby increase employment. Wage subsidy $s_{w}$ urges household $\mathrm{W}$ to move into region $\mathrm{E}$ by raising the total labor income without stimulating local production, and hence this may worsen the local employment.

By applying $L_{1}$ and $L_{2}$ in (15) to (18), substituting $L_{n}^{E}$ in (16) to the result, and noting that $k_{1}=k_{1}(\omega)$ and $k_{2}=k_{2}(\omega)$ from (9), we obtain $\omega$ as a function of $\gamma^{W}, \gamma^{E}$, and $k_{1}^{E}$, where, from the second equation of $(10), k_{1}^{E}$ is a function of $\omega, w^{E}, \epsilon$, and $z$. Thus, by totally differentiating these equations and rearranging the results, we obtain the relationship between $\omega, w^{E}, \gamma^{W}, \gamma^{E}, \epsilon$, and $z$. That is,

$$
\begin{gathered}
A d \omega+\frac{\left(f_{1} k_{2}+\delta f_{2} k_{1}\right) L_{n}^{W}}{k_{2}-k_{1}} d \gamma^{W}+\frac{\gamma^{W}\left(f_{1} k_{2}+\delta f_{2} k_{1}\right) L_{n}^{E}}{\gamma^{E}\left(k_{2}-k_{1}\right)} d \gamma^{E}- \\
\frac{(\omega+\delta) f_{2} k_{1} \gamma^{W} L_{n}^{E}}{p_{1}\left(k_{1}^{E}\right)^{2} f_{1}^{\prime \prime}\left(k_{1}^{E}\right)\left(k_{2}-k_{1}\right)} d w^{E}=-\frac{(\omega+\delta) f_{2} k_{1} \gamma^{W} L_{n}^{E}}{p_{1}\left(k_{1}^{E}\right)^{2} f_{1}^{\prime \prime}\left(k_{1}^{E}\right)\left(k_{2}-k_{1}\right)}\left(w^{E} d \epsilon+d z\right), \\
A=\frac{(\omega+\delta) f_{2}{ }^{2} L_{1}}{\left(k_{2}-k_{1}\right)^{2} f_{1}^{\prime \prime}}+\frac{(\omega+\delta) f_{1}^{2} L_{2}}{\left(k_{2}-k_{1}\right)^{2} \omega^{3} f_{2}^{\prime \prime}}-\delta^{\prime} f_{2} L_{2}+\frac{(\omega+\delta) f_{2} k_{1} \gamma^{W} L_{n}^{E} w^{E}(\varphi-1)}{\omega p_{1}\left(k_{1}^{E}\right)^{2} f_{1}^{\prime \prime}\left(k_{1}^{E}\right)\left(k_{2}-k_{1}\right)},
\end{gathered}
$$

the derivation of which is given in Appendix A. By totally differentiating (13) and substituting $w^{W^{\prime}}(\omega)$ into (9), we have 


$$
\frac{p_{2} f_{2} k_{1}+(1-\varphi) w^{W}\left(k_{2}-k_{1}\right)}{\omega\left(k_{2}-k_{1}\right)} \gamma^{W} d \omega+w^{E} d \gamma^{E}-w^{W} d \gamma^{W}+\gamma^{E} d w^{E}=-\gamma^{E} d s_{w}
$$

Equations (21) and (22) include four endogenous variables, $d w^{E}, d \gamma^{E}, d \omega$, and $d \gamma^{W}$, and three policy variables, $d \varepsilon, d z$, and $d s_{w}$. Equation (20) shows that in each case, two of the four variables are given. Thus, these equations completely determine the policy effects on all the four endogenous variables.

We next derive the welfare effects from the above results. The government replaces land subsidy $S_{r}$ by employment subsidy $z$, wage subsidy $S_{w}$, or production subsidy $\epsilon$; the total amount of lump-sum tax $T$ is fixed,

$$
d T=0
$$

From (10), $k_{1}^{E}$ is a function of $\omega, w^{E}, \epsilon$, and $z$, and from (16), $L_{n}^{E}$ is a function of $\gamma^{E}$ and $k_{1}^{E}$. By substituting these functions into $Y^{E}$ and $Y^{W}$ represented by (12), totally differentiating the results, and taking account of (2), (15), and the second equation of (17), we have

$$
\begin{gathered}
d Y^{E}=-\frac{(1-\varphi)\left(w^{E}+p_{1} f_{1}^{\prime}\left(k_{1}^{E}\right) k_{1}^{E}\right) \gamma^{E}}{\omega} d \omega+w^{E} d \gamma^{E}, \\
d Y^{W}=\frac{(1-\varphi)\left(w^{E}+p_{1} f_{1}^{\prime}\left(k_{1}^{E}\right) k_{1}^{E}\right) \gamma^{E} L_{o}^{E}}{\omega L_{o}^{W}} d \omega+w^{W} d \gamma^{W} .
\end{gathered}
$$

Equations (20), (21), and (22) lead to $d w^{E}, d \gamma^{E}, d \omega$, and $d \gamma^{W}$. Therefore, by applying them to $d Y^{E}$ and $d Y^{W}$, we obtain the policy effects on both regions' income. They straightforwardly imply the welfare effects of subsidy replacement, because the utility of household $j$ (for $j=\mathrm{E}, \mathrm{W}$ ) is $u\left(Y^{j}\right)$ in (5). We obtain them for the four cases summarized in $(20)$. 
Note that neither $d Y^{E}$ nor $d Y^{W}$ in (23) directly depends on the policy variables, $S_{r}, z$, $S_{w}$, and $\epsilon$. This implies that the policy variables affect $Y^{E}$ and $Y^{W}$ only indirectly through changes in the terms of trade and each region's rate of employment, which we call (i) the terms of trade effect and (ii) the employment expansion effect, respectively. In addition to these two effects, replacement policies create another effect, (iii) the effect of redistribution from land owners to firms or workers. When both (2), that is, $L_{o}^{E}=L_{n}^{E}$, and (19), that is, $s_{w}=0, z=0$, and $\epsilon=0$, are valid, this redistribution does not yield any interregional redistribution, as explained below.

By replacing a land subsidy by a wage subsidy, the subsidy payment shifts from land owners to workers in region E. From (19) which implies that the initial wage subsidy is zero, an increase in immigrants creates no transfer to them. From (2), the number of immigrants is negligible, and therefore almost the entire subsidy goes to native workers. Thus, the subsidy transfers due to replacement of the land subsidy by the wage subsidy are almost fully taken by native workers. The land subsidy replacement by employment and production subsidies for local firms go to local land owners as well as native and immigrant workers. However, assuming no immigrants initially, all the increases in employment and production subsidies at the cost of decreasing the land subsidy go to the local land owners and native workers. Thus, the three subsidy replacements create no interregional subsidy redistribution; that is, we find only the terms of trade and employment expansion effects. The mathematical expressions $d Y^{E}$ and $d Y^{W}$ in (23) clarify this property, which is summarized as follows:

Lemma 1: When (2) and (19) hold, there is no interregional redistribution effect; there are only the terms of trade and employment expansion effects. 
Therefore, we focus on the terms of trade and employment expansion effects in the four cases given in (20).

In case of full employment, no employment expansion takes place for native workers in the region. Thus, if the total employment involving native and immigrant workers in the region expands owing to the subsidy policies, the additional revenue goes to the immigrants as wages, while the total income of native households remain invariant. This property is apparent from (23); that is, if the employment rate $\gamma^{j}(j=\mathrm{E}, \mathrm{W})$ equals $1, d \gamma^{j}=0$, and therefore we have only the terms of trade effect. This can be restated as follows:

Lemma 2: The employment expansion effect is zero for household $j(j=E, W)$ if region $j$ is fully employed.

Finally, one naturally assumes that region E specializes in the sector that intensively uses the abundant factor. This property is formally presented as follows:

$$
\begin{aligned}
& \text { Case A: } k_{2}>\frac{K}{L}>k_{1} \geq \frac{K^{E}}{L_{o}^{E}}, \quad k_{2}>\frac{K^{W}}{L_{n}^{W}}>k_{1}, \quad \frac{K^{W}}{L_{o}^{W}}>\frac{K^{E}}{L_{o}^{E}} \\
& \text { Case B: } k_{2}<\frac{K}{L}<k_{1} \leq \frac{K^{E}}{L_{o}^{E}}, \quad k_{2}<\frac{K^{W}}{L_{n}^{W}}<k_{1}, \quad \frac{K^{W}}{L_{o}^{W}}<\frac{K^{E}}{L_{o}^{E}} .
\end{aligned}
$$

\section{3-1. Full employment in both regions}

In (20) case (i), both regions achieve full employment $\left(\gamma^{E}=1, \gamma^{W}=1\right)$; therefore, from (13), (21), and (22), we obtain 


$$
\begin{aligned}
& d \omega=-\frac{(\omega+\delta) f_{2} k_{1} L_{n}^{E}}{p_{1}\left(k_{1}^{E}\right)^{2} f_{1}^{\prime \prime}\left(k_{1}^{E}\right)\left(k_{2}-k_{1}\right) \Omega_{a}}\left(w^{E} d \epsilon+d s_{w}+d z\right), \\
& d w^{W}=d w^{E}+d s_{w} \\
& =\frac{\left(p_{2} f_{2} k_{1}+(1-\varphi) w^{W}\left(k_{2}-k_{1}\right)\right)(\omega+\delta) f_{2} k_{1} L_{n}^{E}}{p_{2}\left(k_{1}^{E}\right)^{2} f_{1}^{\prime \prime}\left(k_{1}^{E}\right)\left(k_{2}-k_{1}\right)^{2} \Omega_{a}}\left(w^{E} d \epsilon+d z+d s_{w}\right), \\
& \gamma^{E}=1, \gamma^{W}=1
\end{aligned}
$$

where

$$
\Omega_{a}=\frac{(\omega+\delta) f_{2}{ }^{2} L_{1}}{\left(k_{2}-k_{1}\right)^{2} f_{1}^{\prime \prime}}+\frac{(\omega+\delta) f_{1}^{2} L_{2}}{\left(k_{2}-k_{1}\right)^{2} \omega^{3} f_{2}^{\prime \prime}}+\frac{(\omega+\delta) L_{n}^{E}}{f_{1}^{\prime \prime}\left(k_{1}^{E}\right)}\left(\frac{f_{2} k_{1}}{k_{1}^{E}\left(k_{2}-k_{1}\right)}\right)^{2}-\delta^{\prime} f_{2} L_{2}<0 .
$$

The first equation of (25) implies that

$$
\left.S_{w} \uparrow, \epsilon \uparrow, z \uparrow \Rightarrow \omega \downarrow \text { (or } \uparrow\right) \quad \text { if } k_{2}>k_{1} \text { (or } k_{2}<k_{1} \text { ). }
$$

Therefore, from (23), where $\gamma^{E}=1$ and $\gamma^{W}=1$, we have

$$
\begin{aligned}
& \frac{d Y^{E}}{d \sigma}=-\left(\frac{(1-\varphi)\left(w^{E}+p_{1} f_{1}^{\prime}\left(k_{1}^{E}\right) k_{1}^{E}\right) \gamma^{E}}{\omega}\right) \frac{d \omega}{d \sigma} \gtrless 0, \\
& \frac{d Y^{W}}{d \sigma}=\left(\frac{(1-\varphi)\left(w^{E}+p_{1} f_{1}^{\prime}\left(k_{1}^{E}\right) k_{1}^{E}\right) \gamma^{E} L_{o}^{E}}{\omega L_{o}^{W}}\right) \frac{d \omega}{d \sigma} \lessgtr 0,
\end{aligned}
$$

if $k_{2} \gtrless k_{1}$ for $\sigma=s_{w}, \epsilon, z$.

Because the utility of household $j(=E, W)$ is $u\left(Y^{j}\right)$, as shown in (5), we have the following proposition.

Proposition 1: If full employment prevails in both regions, replacing a land subsidy by wage, employment, and production subsidies makes household E better (worse) off and household $W$ worse (better) off when region $E$ specializes in the labor-intensive (land-intensive) commodity. 
When full employment prevails, from Lemmas 1 and 2, there is neither the interregional redistribution effect nor the employment expansion effect. Hence, we have only the terms of trade effect. Replacement policies first raise the labor income in region E, and then increase the wage in region $\mathrm{W}$, as shown in (25); this raises the price of the labor-intensive commodity. Therefore, if region E's product is labor-intensive, it benefits region $\mathrm{E}$ but harms region $\mathrm{W}$ through the terms of trade effect. If region E's product is land-intensive, it harms region $\mathrm{E}$ but benefits region $\mathrm{W}$.

\section{3-2. Unemployment in both regions}

In (20) case (ii), where the wages in both regions are fixed, we have from (21) and $(22)$,

$$
\begin{aligned}
& d \gamma^{E}=-\frac{f_{2} k_{1} \gamma^{E} L_{n}^{E}(\omega+\delta)}{p_{1}\left(k_{1}^{E}\right)^{2} f_{1}^{\prime \prime}\left(k_{1}^{E}\right)\left(f_{1} k_{2}+\delta f_{2} k_{1}\right) L}\left(\bar{w}^{E} d \epsilon+d z\right)-\frac{\gamma^{E} L_{n}^{W}}{\bar{w}_{L}} d s_{w}, \\
& d \gamma^{W}=-\frac{L_{n}^{E} \gamma^{W} f_{2} k_{1}(\omega+\delta)}{p_{1}\left(k_{1}^{E}\right)^{2} f_{1}^{\prime \prime}\left(k_{1}^{E}\right)\left(f_{1} k_{2}+\delta f_{2} k_{1}\right) L}\left(\bar{w}^{E} d \epsilon+d z\right)+\frac{\gamma^{W} L_{n}^{E}}{\bar{w}^{E} L} d s_{w}, \\
& d w^{E}=0, \quad d \omega=0 .
\end{aligned}
$$

By substituting $d \gamma^{W}$ and $d \gamma^{E}$ in (26) to (23), we obtain the income effect on household $\mathrm{E}$ as well as that on household $\mathrm{W}$ :

$$
\begin{aligned}
& d Y^{E}=-\frac{L_{n}^{E} \gamma^{E} \bar{w}^{E} f_{2} k_{1}(\omega+\delta)}{p_{1}\left(k_{1}^{E}\right)^{2} f_{1}^{\prime \prime}\left(k_{1}^{E}\right)\left(f_{1} k_{2}+\delta f_{2} k_{1}\right) L}\left(\bar{w}^{E} d \epsilon+d z\right)-\frac{\gamma^{E} L_{O}^{W}}{L} d s_{w}, \\
& d Y^{W}=-\frac{L_{n}^{E} \gamma^{W} \bar{w}^{W} f_{2} k_{1}(\omega+\delta)}{p_{1}\left(k_{1}^{E}\right)^{2} f_{1}^{\prime \prime}\left(k_{1}^{E}\right)\left(f_{1} k_{2}+\delta f_{2} k_{1}\right) L}\left(\bar{w}^{E} d \epsilon+d z\right)+\frac{\bar{w}^{W} \gamma^{W} L_{n}^{E}}{\bar{w}^{E} L} d s_{w} .
\end{aligned}
$$

Because $f_{1}^{\prime \prime}<0$, the above equations imply that

$$
\begin{gathered}
d Y^{E} / d \epsilon>0, d Y^{E} / d z>0, d Y^{E} / d s_{w}<0 \\
d Y^{W} / d \epsilon>0, d Y^{W} / d z>0, d Y^{W} / d s_{w}>0 .
\end{gathered}
$$

These properties are formally restated in the following proposition: 
Proposition 2: In case of unemployment in regions $W$ and E, replacing a land subsidy by production and employment subsidies makes both households better off, whereas replacing it by a wage subsidy makes household $E$ worse off and household $W$ better off.

In region $\mathrm{W}$, where both commodities are produced, the relative price does not change because of wage rigidity; this implies that the terms of trade effect does not exist. From Lemma 1, there is no interregional redistribution effect. Thus, only the employment expansion effect exists. Replacement with production and employment subsidies expands region E's production as well as the native and immigrant employment, making both the regions better off. The wage subsidy does not change the wages of both regions' firms, and so the production of neither region is affected. However, some workers in region W may move to region $\mathrm{E}$ and take up some employment there. Thus, the employment expansion effect is positive for household $\mathrm{W}$ but negative for household $\mathrm{E}$, making the former better off and the latter worse off.

\section{3-3. Full employment in region $E$ and unemployment in region $W$}

In (20) case (iii), where the wage in region $\mathrm{W}$ is fixed, from (21) and (22), we obtain

$$
\begin{gathered}
d \gamma^{W}=\frac{(\omega+\delta) f_{2} k_{1} \gamma^{W} L_{n}^{E}}{p_{1}\left(k_{1}^{E}\right)^{2} f_{1}^{\prime \prime}\left(k_{1}^{E}\right)\left(f_{1} k_{2}+\delta f_{2} k_{1}\right) L_{n}^{W} \Omega_{b}}\left(w^{E} d \epsilon+d s_{w}+d z\right), \\
d w^{E}=\frac{(\omega+\delta) f_{2} k_{1} \gamma^{W} \bar{w}_{L_{n}} W_{1}}{p_{1}\left(k_{1}^{E}\right)^{2} f_{1}^{\prime \prime}\left(k_{1}^{E}\right)\left(f_{1} k_{2}+\delta f_{2} k_{1}\right) L_{n}^{W} \Omega_{b}}\left(w^{E} d \epsilon+d z\right)+\frac{d s_{W}}{\Omega_{b}}, \\
\gamma^{E}=1, d \omega=0,
\end{gathered}
$$

where 


$$
\Omega_{b}=\frac{(\omega+\delta) f_{2} k_{1} \gamma^{W} L_{n}^{E} \bar{w}^{W}}{p_{1}\left(k_{1}^{E}\right)^{2} f_{1}^{\prime \prime}\left(k_{1}^{E}\right)\left(f_{1} k_{2}+\delta f_{2} k_{1}\right) L_{n}^{W}}-1<0 .
$$

Therefore, the first equation in (27) implies that

$$
S_{w} \uparrow, \epsilon \uparrow, z \uparrow \rightarrow \gamma^{W} \uparrow .
$$

By substituting (27) into (23), we obtain the effects of subsidy replacements on the income of household E (or W). They satisfy

$$
d Y^{E}=0, d Y^{W}>0
$$

Because the wage rate in region $\mathrm{W}$ is fixed and both commodities are produced, the relative commodity price is fixed. Thus, the terms of trade effect does not exist. Furthermore, Lemma 1 implies that the interregional redistribution effect does not exist. As regards the employment expansion effect, replacing land subsidy with the other subsidies urges workers to come to region $\mathrm{E}$, and this improves the employment situation of household W, implying a positive employment expansion effect for household W. However, no employment expansion occurs for household E because it is fully employed. Thus, there is no effect on household E's utility.

Proposition 3: In case of full employment in region $E$ and unemployment in region $W$, all the subsidy replacements increase the utility of household $W$ while the utility of household $E$ remains unaffected.

\section{3-4. Unemployment in region $E$ and full employment in region $W$}

In (20) case (iv), where $w^{E}=\bar{w}^{E}$, from (21) and (22), we obtain 


$$
\begin{aligned}
& d \omega=-\frac{(\omega+\delta) L_{n}^{E} f_{2} k_{1}}{p_{1}\left(k_{1}^{E}\right)^{2} f_{1}^{\prime \prime}\left(k_{1}^{E}\right)\left(k_{2}-k_{1}\right) \Omega_{c}}\left(\bar{w}^{E} d \epsilon+d z\right)+\frac{\left(f_{1} k_{2}+\delta f_{2} k_{1}\right) L_{n}^{E}}{\bar{w}^{E}\left(k_{2}-k_{1}\right) \Omega_{c}} d s_{w}, \\
& d \gamma^{E}=\frac{\left(\varphi f_{2} k_{1}+(1-\varphi)\left(f_{2}-f_{2}^{\prime}\left(k_{2}-k_{1}\right)\right) k_{2}\right)(\omega+\delta) f_{2} k_{1} L_{n}^{E}}{\left(k_{1}^{E}\right)^{2} f_{1}^{\prime \prime}\left(k_{1}^{E}\right) Y\left(k_{2}-k_{1}\right)^{2} \Omega_{c}}\left(\bar{w}^{E} d \epsilon+d z\right)-\frac{\gamma^{E} B}{\bar{w}^{E} \Omega_{c}} d s_{w}, \\
& d w^{E}=0, \quad \gamma^{W}=1,
\end{aligned}
$$

where

$$
\begin{gathered}
\Omega_{c}=\frac{(\omega+\delta) f_{2}{ }^{2} L_{1}}{\left(k_{2}-k_{1}\right)^{2} f_{1}^{\prime \prime}}+\frac{(\omega+\delta) f_{1}^{2} L_{2}}{\left(k_{2}-k_{1}\right)^{2} \omega^{3} f_{2}^{\prime \prime}}-\delta^{\prime} f_{2} L_{2} \\
-\frac{p_{1} f_{2}\left(f_{1} k_{2}+\delta f_{2} k_{1}\right) L_{n}^{E}}{\left(k_{2}-k_{1}\right)^{2}}\left(\frac{k_{1}}{\gamma^{E} \bar{w}^{E}}+\frac{\left(k_{2}-k_{1}\right) L_{2}}{Y}\right)-\frac{f_{2}{ }^{2} L_{2} L_{n}^{E}(\omega+\delta) \bar{w}^{E} k_{1}}{\left(k_{1}^{E}\right)^{2} f_{1}^{\prime \prime}\left(k_{1}^{E}\right)\left(k_{2}-k_{1}\right) Y}<0, \\
B=\frac{(\omega+\delta) f_{2}{ }^{2} L_{1}}{\left(k_{2}-k_{1}\right)^{2} f_{1}^{\prime \prime}}+\frac{(\omega+\delta) f_{1}^{2} L_{2}}{\left(k_{2}-k_{1}\right)^{2} \omega^{3} f_{2}^{\prime \prime}}-\delta^{\prime} f_{2} L_{2}-\frac{f_{2}{ }^{2} L_{2} L_{n}^{E}(\omega+\delta) \bar{w}^{E} k_{1}}{\left(k_{1}^{E}\right)^{2} f_{1}^{\prime \prime}\left(k_{1}^{E}\right)\left(k_{2}-k_{1}\right) Y}\left(<0 \text { if } k_{2}<k_{1}\right),
\end{gathered}
$$

and $\Omega_{c}$ is the derivative of the left-hand side of (18) with respect to $\omega$. Because the left-hand side of (18) is the supply-value ratio of commodity 1 to commodity 2 minus the demand-value ratio, it must decline as $\omega$ rises; that is, $\Omega_{c}$ is negative. Therefore,

$$
\begin{gathered}
s_{w} \uparrow, \epsilon \uparrow, z \uparrow \Rightarrow \omega \downarrow(\text { or } \uparrow) \quad \text { if } k_{2}>k_{1}\left(\text { or } k_{2}<k_{1}\right) ; \\
\epsilon \uparrow, z \uparrow \Rightarrow \gamma^{E} \uparrow ; \\
s_{w} \uparrow \Rightarrow \gamma^{E} \downarrow \text { if } k_{2}<k_{1} .
\end{gathered}
$$

Because an increase in production, employment, and wage subsidies raises the expected labor income in region $\mathrm{E}$, the wage in region $\mathrm{W}$ also rises. Therefore, the relative price of the labor-intensive commodity increases, as the first line in (29) shows. As for the effect on the employment rate in region $\mathrm{E}$, an increase in production and employment subsidies expands the employment and production in region E, and hence raises $\gamma^{E}$. An increase in wage subsidy $s_{w}$ urges the workers in region $\mathrm{W}$ to move to region $\mathrm{E}$ without directly stimulating the production in region $\mathrm{E}$, and so the employment rate $\gamma^{E}$ declines. Moreover, if $k_{2}<k_{1}, \omega$ increases, as shown in (29), which lowers the price of the local 
commodity in region $\mathrm{E}$ and urges the local firms to reduce $\gamma^{E}$ further. If $k_{2}>k_{1}$, however, $\omega$ decreases, which increases $p_{1}(\omega)$, urges the local firms to increase employment, and hence makes the sign of $d \gamma^{E} / d s_{w}$ ambiguous.

Using (29), one finds that $d Y^{E}$ and $d Y^{W}$ given in (23) satisfy

$$
\begin{gathered}
\frac{d Y^{W}}{d \sigma}=\frac{(1-\varphi)\left(w^{E}+p_{1} f_{1}^{\prime}\left(k_{1}^{E}\right) k_{1}^{E}\right) \gamma^{E} L_{o}^{E}}{\omega L_{o}^{W}} \frac{d \omega}{d \sigma} \lessgtr 0 \text { if } k_{2} \gtrless k_{1} ; \\
\frac{d Y^{E}}{d \sigma}=-\frac{(1-\varphi)\left(w^{E}+p_{1} f_{1}^{\prime}\left(k_{1}^{E}\right) k_{1}^{E}\right) \gamma^{E}}{\omega} \frac{d \omega}{d \sigma}+w^{E} \frac{d \gamma^{E}}{d \sigma} ; \\
\text { for } \sigma=s_{w}, \epsilon, z .
\end{gathered}
$$

From Lemma 1, there is no interregional redistribution. Because of full employment in region $\mathrm{W}$, the employment expansion effect for household $\mathrm{W}$ is zero, as Lemma 2 shows. Thus, only the terms of trade effect exists for household W, which is explicitly exhibited by the first equation in (30).

Because region $\mathrm{E}$ is underemployed, both the terms of trade effect and employment expansion effect exist, as the second equation in (30) shows. To find the total welfare effect on household E, we compare the two effects. Applying the properties in (29) to the second equation in (30) yields

$$
\begin{gathered}
d Y^{E} / d z>0, d Y^{E} / d \epsilon>0 \text { if } k_{2}>k_{1} \\
d Y^{E} / d s_{w}<0 \text { if } k_{2}<k_{1} .
\end{gathered}
$$

From (29), the terms of trade effect on household $\mathrm{E}$ is positive (or negative) when the local commodity is labor-intensive (land-intensive). Employment and production subsidies, $Z$ and $\epsilon$, expand the employment in region $\mathrm{E}$ and make household $\mathrm{E}$ better off. Thus, if the local commodity is labor-intensive (i.e., $k_{2}>k_{1}$ ), both the terms of trade effect and employment expansion effect of the two subsidies are positive, making household E better 
off, as the first line in (31) shows. If the local commodity is land-intensive, however, the two effects have opposite directions and the welfare effect becomes ambiguous.

A wage subsidy urges household $\mathrm{W}$ to move to region $\mathrm{E}$, decreasing the employment rate in region $\mathrm{E}$. This raises the expected labor income in region $\mathrm{E}$ and the wage in region $\mathrm{W}$, and hence increases the relative price of the labor-intensive commodity. Thus, if the local commodity in region $\mathrm{E}$ is land-intensive, the wage subsidy not only lowers the local employment rate, but also worsens the terms of trade, making household E worse off. If the local commodity in region $\mathrm{E}$ is labor-intensive, however, the terms of trade improves whereas the employment rate worsens, and the welfare effect on household E becomes ambiguous.

Specific utility and production functions: In order to explicitly show that the effects of the employment and production subsidies on household E's utility can indeed be positive and negative when the local commodity is land-intensive, and that the effect of the wage subsidy on household E's utility can be positive and negative when the local commodity is labor-intensive, we assume the following specific utility and production functions:

$$
u=c_{1}^{\varphi} c_{2}^{1-\varphi}, f_{1}\left(k_{1}\right)=k_{1}^{\alpha}, f_{2}\left(k_{2}\right)=k_{2}^{\beta} \text { where } \alpha, \beta, \varphi \in(0,1)
$$

and consider the case where the employment rate in region $\mathrm{E}$ is almost unity,

$$
\gamma^{E} \approx 1
$$

We show below that in this specific case, the effects on household E's utility can be positive and negative depending on some parameter values. Thus, generally, the effects can indeed be positive and negative. 
The welfare effect of the wage subsidy on household $\mathbf{E}$ when $\boldsymbol{k}_{2}>\boldsymbol{k}_{1}$ : In this case, the sign of $d Y^{E} / d s_{w}$ is ambiguous. As proved in Appendix $\mathrm{B}$, the $L_{1}=0$ curve is

$$
\varphi=\varphi^{c}\left(\equiv \frac{\beta K^{E}}{\alpha K^{W}+\beta K^{E}}\right)
$$

which is shown in Figure 1, and the boundary that makes $d Y^{E} / d s_{w}$ positive or negative is as depicted in Figure 1.

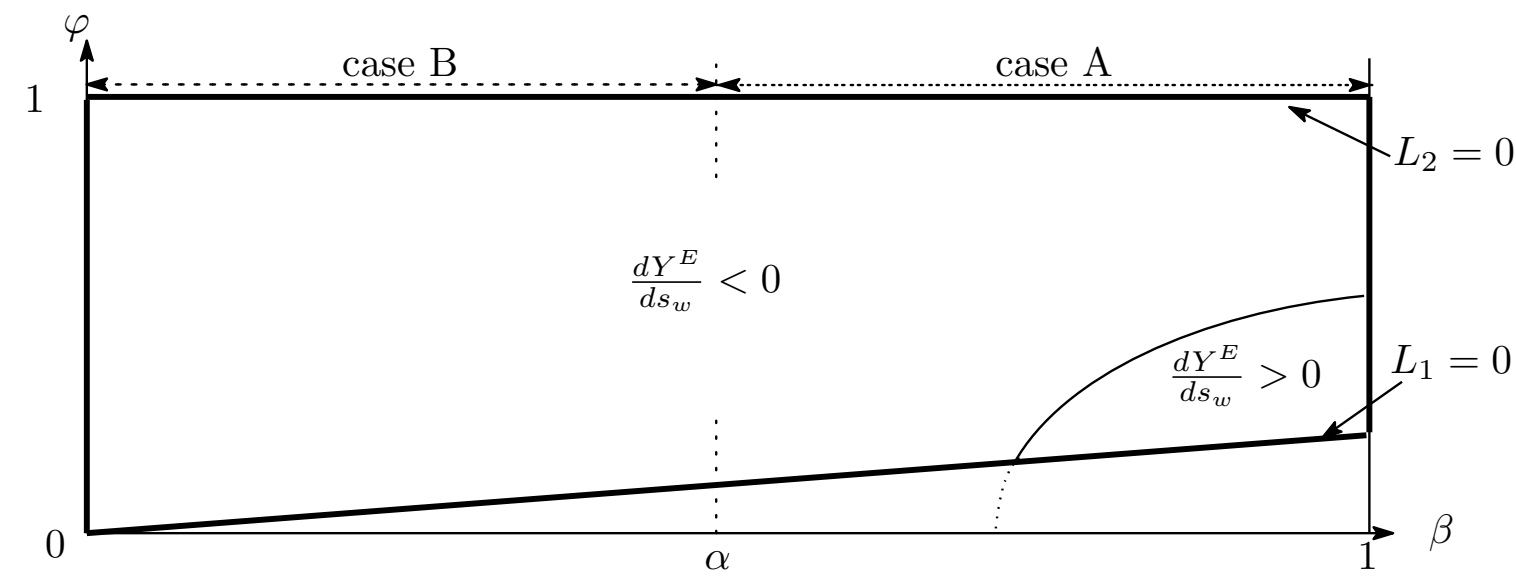

Figure 1. The sign of $d Y^{E} / d s_{w}$

Replacing a land subsidy with a wage subsidy urges the workers to move from region $\mathrm{W}$ to region $\mathrm{E}$, and this worsens the employment rate in region $\mathrm{E}$, harming household $\mathrm{E}$. It however raises the wage in region $\mathrm{W}$ and the relative price of the labor-intensive commodity, that is, commodity 1 in the present case. Thus, the terms of trade of household E improves, benefiting household E. If the beneficial effect of the improvement in terms of trade dominates the negative effect of the decrease in employment, household $\mathrm{E}$ is better off. The magnitude of the two effects depends on the values of $\varphi$ and $\beta$. If $\varphi$ is low, the ratio of consumption expenditure on commodity 2 is large, and hence the benefit due to the decline in $\omega$ is large, as is clear from the expression of $d Y^{E} / d s_{w}$ in (30). Moreover, if $\beta$ is close to 1 but $\alpha$ is not, the production of commodity 2 does not require much labor, but that 
of commodity 1 does. Thus, an increase in wage raises the production cost of commodity 2 a little, while the cost of commodity 1 significantly rises, making $\omega$ broadly decline. Because the benefit and magnitude of the decline in $\omega$ are both large, the positive terms of trade effect is significant, and dominates the negative employment expansion effect.

The welfare effect of the production and employment subsidies on household $\mathbf{E}$ when $\boldsymbol{k}_{\mathbf{2}}<\boldsymbol{k}_{\mathbf{1}}$ : As shown in Appendix $\mathrm{C}$, the boundary that makes $d Y^{E} / d \sigma$ (for $\sigma=\epsilon, z$ ) positive or negative is as illustrated in Figure 2.

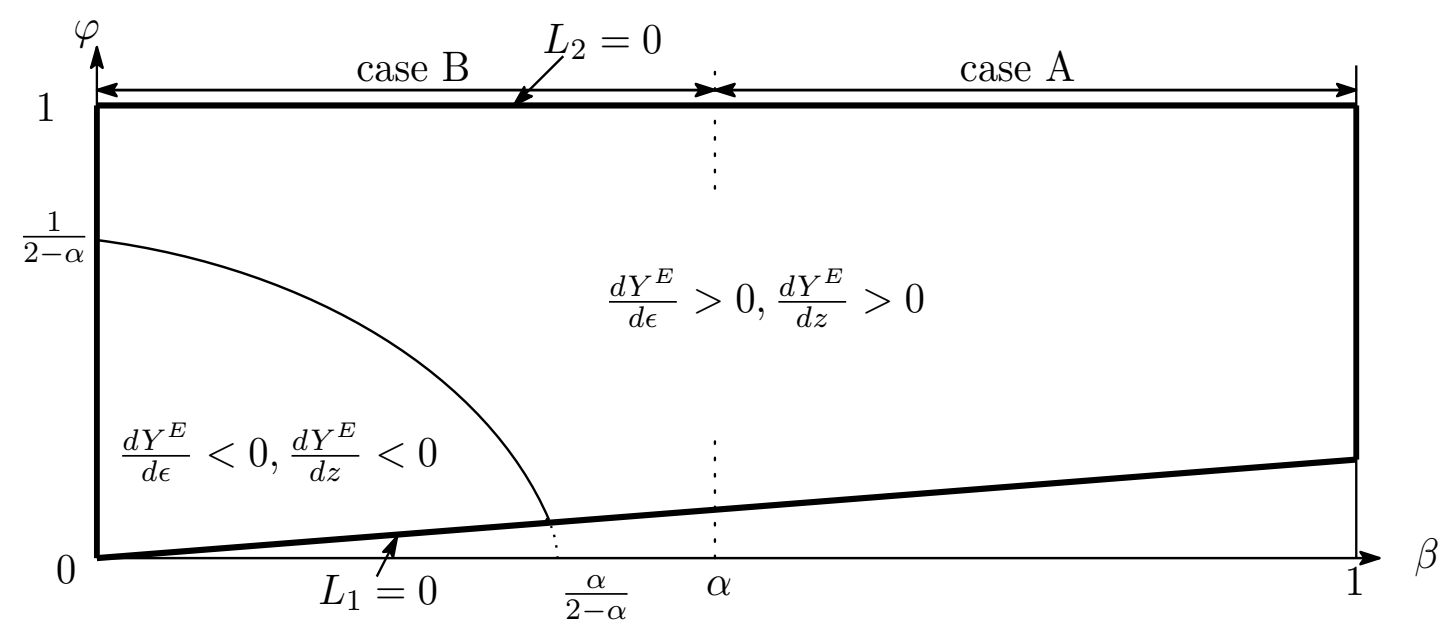

Figure 2. The sign of $d Y^{E} / d \sigma($ for $\sigma=\epsilon, z)$

Replacing a land subsidy with production and employment subsidies expands the employment in region $\mathrm{E}$, benefiting household $\mathrm{E}$. It however raises the wage in region $\mathrm{W}$ as well as the relative price of the labor-intensive commodity, that is, commodity 2 in the present case. Thus, the terms of trade of household E deteriorates. The magnitude of the employment expansion and terms of trade effects depends on the values of $\varphi$ and $\beta$. If $\varphi$ is low, the ratio of consumption expenditure on commodity 2 is large, and hence the harm due 
to the rise in $\omega$ is large, as mentioned in the previous subsection. Moreover, if $\beta$ is small and $\alpha$ is large, the production of commodity 2 requires much more labor than that of commodity 1 , and the wage increase raises the production cost of commodity 2 much more than the production cost of commodity 1 , significantly raising $\omega$. Thus, both the harm and magnitude of the rise in $\omega$ are large, and the negative terms of trade effect is so large that it dominates the positive employment expansion effect, making household E worse off.

Summary: The results of (30), (31), and the two figures are summarized as follows:

\begin{tabular}{|l|l|c|c|}
\hline & \multicolumn{2}{|c|}{ Household E } & Household W \\
\hline \multirow{2}{*}{ case A: } & \multicolumn{2}{|c|}{$d u^{E} / d \epsilon>0, d u^{E} / d z>0$} & $d u^{W} / d \epsilon<0$ \\
$k_{2}>k_{1}$ & $\varphi \approx 1$ & $d u^{E} / d s_{w}<0$ & $d u^{W} / d z<0$ \\
\cline { 2 - 4 } & $\varphi \approx \varphi^{c}, \beta \approx 1$ & $d u^{E} / d s_{w}>0$ & $d u^{W} / d s_{w}<0$ \\
\hline \multirow{2}{*}{$k_{2}<k_{1}$} & $\varphi \approx 1$ & $d u^{E} / d \epsilon \geq 0, d u^{E} / d z \geq 0$ & $d u^{W} / d \epsilon>0$ \\
\cline { 2 - 4 } & $\varphi \approx \varphi^{c}, \beta \approx 0$ & $d u^{E} / d \epsilon<0, d u^{E} / d z<0$ & $d u^{W} / d z>0$ \\
\cline { 2 - 4 } & \multicolumn{2}{|c}{$d u^{E} / d s_{w}<0$} & $d u^{W} / d s_{w}>0$ \\
\hline
\end{tabular}

In the above expressions, $\varphi^{c}$ is given by (33). Therefore, we have the following proposition:

Proposition 4: In case of unemployment in region $E$ and full employment in region $W$, subsidy replacements possess the following properties: 
Case $A\left(k_{2}>k_{1}\right)$ : All the replacement policies decrease $\omega$ and household W's utility. Production and employment subsidies increase household E's utility. A wage subsidy can make household E better off and worse off. Under the utility and production functions given in (32), the welfare effect on household $E$ is negative when the ratio of consumption expenditure on commodity 1 is large. However, it is positive when $\beta$ is close to 1 and the ratio of consumption expenditure on commodity 1 is so small that region $W$ almost specializes in commodity 2.

Case B $\left(k_{2}<k_{1}\right)$ : All the replacement policies increase $\omega$ and household W's utility. $A$ wage subsidy makes household E worse off. The welfare effects of production and employment subsidies on household E are ambiguous. Under the utility and production functions given in (32), the effects are positive when the ratio of consumption expenditure on commodity 1 is large. However, they are negative when $\beta$ is small and the ratio of consumption expenditure on commodity 1 is so small that region $W$ almost specializes in commodity 2.

\section{Concluding Remarks}

A government offering a subsidy to a local region can choose between a lump-sum transfer and various other subsidies that affect local economic activities. Using a two-region two-commodity two-factor model in which the subsidy recipient region produces only one of the two commodities because of lack of technology, we analyzed the welfare effects of replacing a lump-sum transfer by production, employment, and wage subsidies on the recipient and non-recipient regions under various full employment and underemployment combinations. 
If the recipient region's wage is flexible and full employment prevails, the replacement policies urge workers to migrate to the recipient region because the labor income in that region increases. The wage of the non-recipient region also increases if it is flexible, and the price of the labor-intensive commodity rises. If the recipient region specializes in the labor-intensive (land-intensive) commodity, the terms of trade in this region improves (deteriorates), and the native households of the region is better (worse) off. If unemployment prevails in the non-recipient region, the relative price does not vary and subsidy replacements have no effect on the recipient region.

If unemployment prevails in the recipient region, replacing a lump-sum subsidy with production and employment subsidies expands employment and benefit the region. However, a wage subsidy does not stimulate local production, but urges workers to move into the region, and this worsens local employment and harms the recipient region. If the non-recipient region also suffers from underemployment, the relative commodity price shows no change. Therefore, only the employment effect matters; that is, production and employment subsidies benefit, and a wage subsidy harms, the recipient region.

If the non-recipient region achieves full employment and the recipient region remains underemployed, the three subsidies raise the wage in the non-recipient region and increase the labor-intensive commodity's price. Thus, if the recipient region's local product is labor-intensive, the region's terms of trade improves. Moreover, production and employment subsidies increase local employment. Therefore, they definitely make the recipient region better off. A wage subsidy, however, worsens the region's local employment. Thus, it reduces, or even dominates, the benefit due to the improvement in terms of trade. If the local product is land-intensive, however, the three subsidies worsen the recipient region's terms of trade. Therefore, a wage subsidy always harms the recipient 
region through two channels: deteriorating the terms of trade and decreasing the employment rate. Production and employment subsidies, however, expand local employment and alleviate, or even dominate, the harm due to the deterioration in the terms of trade.

Nowadays, several developed countries, including the EU and Japan, show declining birth rates, especially in urban areas, and migrations from rural to urban areas. For a future study, the present model can be extended to these problems and applied to analyze the welfare effects on rural and urban areas of population changes and subsidy policies affecting interregional immigrations.

\section{Appendices}

\section{Appendix A}

By totally differentiating (18), where $L_{1}$ and $L_{2}$ are given by (15) and $L_{n}^{E}$ is given by (16), we obtain

$$
A \cdot d \omega+\frac{\left(f_{1} k_{2}+\delta f_{2} k_{1}\right) L_{n}^{W}}{k_{2}-k_{1}} d \gamma^{W}+\frac{\gamma^{W}\left(f_{1} k_{2}+\delta f_{2} k_{1}\right) L_{n}^{E}}{\gamma^{E}\left(k_{2}-k_{1}\right)} d \gamma^{E}+\frac{(\omega+\delta) f_{2} k_{1} \gamma^{W} L_{n}^{E}}{k_{1}^{E}\left(k_{2}-k_{1}\right)} d k_{1}^{E}=0
$$

where, because $p_{2} f_{2}=r^{W} k_{2}+w^{W}$ from (8), we have

$$
A=\frac{(\omega+\delta) f_{2}^{2} L_{1}}{\left(k_{2}-k_{1}\right)^{2} f_{1}^{\prime \prime}}+\frac{(\omega+\delta) f_{1}^{2} L_{2}}{\left(k_{2}-k_{1}\right)^{2} \omega^{3} f_{2}^{\prime \prime}}-\delta^{\prime} f_{2} L_{2}<0 .
$$

By totally differentiating the second equation of (10), we have

$$
d k_{1}^{E}=\frac{w^{E} d \varepsilon+\left(w^{E}(\varphi-1) / \omega\right) \cdot d \omega-d w^{E}+d z}{p_{1} k_{1}^{E} f_{1}^{\prime \prime}\left(k_{1}^{E}\right)} .
$$

Substituting this $d k_{1}^{E}$ into (A1) and rearranging the result yields (21).

\section{Appendix B}


Applying the utility and production functions in (32) to the two equations in (8) yields

$$
\frac{f_{1}}{k_{1}} / \frac{f_{2} \omega}{k_{2}}=\frac{\beta}{\alpha}
$$

Because $L_{2}=\left(K^{W}-k_{1} L_{1}\right) / k_{2}$, from the first equation in (14), substituting $L_{2}$ and the above equation into (18) when $\gamma^{E} \approx 1$ gives

$$
L_{1}=\frac{\frac{\varphi}{1-\varphi} K^{W}-\frac{\beta}{\alpha} K^{E}}{\left(\frac{\beta}{\alpha}+\frac{\varphi}{1-\varphi}\right) k_{1}} .
$$

Since both commodities are produced in region $\mathrm{W}, L_{1}$, given above, must be positive, and thus

$$
\varphi>\frac{\beta K^{E}}{\alpha K^{W}+\beta K^{E}} \equiv \varphi^{c}
$$

Note that region $\mathrm{W}$ produces only commodity 2 (i.e., $L_{1}=0$ ) when $\varphi=\varphi^{c}$. Thus, the $L_{1}=0$ curve in Figures 1 and 2 shows the curve of $\varphi=\varphi^{c}$ given in (33).

Substituting $d \omega$ and $d \gamma^{E}$ in (28) into $d Y^{E}$ in (30) gives

$$
\frac{d Y^{E}}{d s_{w}}=-\frac{\left(f_{1} k_{2}+\delta f_{2} k_{1}\right) L_{n}^{E}}{\omega \bar{w}^{E}\left(k_{2}-k_{1}\right)^{2} \Omega_{c}} \eta_{1}
$$

where

$$
\begin{aligned}
\eta_{1}= & (1-\varphi)\left(k_{2}-k_{1}\right)\left(w^{W}+r^{E} \gamma^{E} k_{1}^{E}-\frac{(\omega+\delta) f_{2} \gamma^{E}\left(w^{E}\right)^{2}}{p_{1}\left(f_{1} k_{2}+\delta f_{2} k_{1}\right) k_{1} f_{1}^{\prime \prime}}\right) \\
& +\frac{\omega \gamma^{E} \bar{w}^{E}\left(k_{2}-k_{1}\right)^{2}}{\left(f_{1} k_{2}+\delta f_{2} k_{1}\right) L_{n}^{E}}\left(\frac{(\omega+\delta) f_{2}{ }^{2} L_{1}}{\left(k_{2}-k_{1}\right)^{2}{f_{1}^{\prime \prime}}^{\prime \prime}}+\frac{(\omega+\delta) f_{1}^{2} L_{2}}{\left(k_{2}-k_{1}\right)^{2} \omega^{3} f_{2}^{\prime \prime}}-\delta^{\prime} f_{2} L_{2}\right) .
\end{aligned}
$$

Applying the production functions in (32) to $\eta_{1}$ yields

$$
\eta_{1}=\frac{k_{1}^{1+\alpha} p_{1}\left[(1-\varphi)(\beta-\alpha)((\beta-\alpha)(1-\varphi)+1) L_{n}^{E}-\left(\alpha(1-\alpha) L_{1}+\beta(1-\beta) L_{2}\right)\right]}{\alpha(1-\beta)(\beta(1-\varphi)+\alpha \varphi) L_{n}^{E}} .
$$

The boundary curve in Figure 1 is the relationship between $\beta$ and $\varphi$, which makes $\eta_{1}$ equal to zero: 


$$
(1-\varphi)(\beta-\alpha)((\beta-\alpha)(1-\varphi)+1) L_{n}^{E}=\left(\alpha(1-\alpha) L_{1}+\beta(1-\beta) L_{2}\right)
$$

In case $k_{1}<k_{2}$, it holds that $\alpha<\beta$ when the production functions are given by (32). Thus, we find that $d Y^{E} / d s_{w}<0$ above the boundary curve and $d Y^{E} / d s_{w}>0$ below the curve.

\section{Appendix C}

In case $k_{1}>k_{2}$, we obtain $\alpha>\beta$ when the production functions are given by (32). The effects of $\epsilon$ and $z$ on $Y^{E}$ given in (30) become

$$
\begin{gathered}
d Y^{E}=\frac{L_{n}^{E} f_{2} k_{1}^{\alpha+2}(\omega+\delta)\left(\bar{w}^{E} d \epsilon+d z\right)}{\alpha(1-\beta) \omega\left(k_{1}^{E}\right)^{2} f_{1}^{\prime \prime}\left(k_{1}^{E}\right)\left(k_{2}-k_{1}\right)^{2} \Omega_{c}} \eta_{2}, \\
\text { where } \eta_{2}=\alpha(1-\alpha)+(1-\varphi)(\beta-\alpha)(2-\alpha), \alpha>\beta,
\end{gathered}
$$

implying that the sign of $d Y^{E} / d z$ and $d Y^{E} / d \epsilon$ is the same as the sign of $\eta_{2}$. The condition under which $\eta_{2} \gtrless 0$ is

$$
\varphi \gtrless 1+\frac{\alpha(1-\alpha)}{(\beta-\alpha)(2-\alpha)} .
$$

Figure 2 illustrates this property.

\section{References}

Albouy, D. (2012) "Evaluating the Efficiency and Equity of Federal Fiscal Equalization", Journal of Public Economics, 96(9-10), pp. 824-839.

Batra, R. N., and N. Naqvi (1987) "Urban Unemployment and the Gains from Trade", Economica, 54(215), pp. 381-395.

Besfamille, M. and J. Lozachmeur (2010) "NIMBY and Mechanism Design under Different Constitutional Constraints", International Tax and Public Finance, 17(2), pp. $114-132$. 
Bhagwati, J., and T. Srinivasan (1974) “On Reanalyzing the Harris-Todaro Model: Policy Rankings in the Case of Sector-specific Sticky Wages", American Economic Review, 64(3), pp. 502-508.

Boadway, R. and F. Flatters (1982) "Efficiency and Equalization Payments in a Federal System of Government: A Synthesis and Extension of Recent Results", Canadian Journal of Economics, 15(4), pp. 613-633.

Brueckner J. K. and Y. Zenou (1999) "Harris-Todaro Models with a Land Market", Reginal Science and Urban Economics, 29(3), pp. 317-339.

Brueckner, J. K. and H. A. Kim (2001) "Land Markets in the Harris-Todaro Model: A New Factor Equilibrating Rural-Urban Migration”, Journal of Regional Science, 41(3), pp. $507-520$.

Choi, J.-Y. and E. S. H. Yu (2010) "Imperfect Capital Mobility: A General Approach to the Two-Sector Harris Todaro Model", Review of International Economics, 18(1), pp. 81-94.

Corden, W. M., and R. Findlay (1975) "Urban Unemployment, Intersectoral Capital Mobility and Development Policy", Economica, 42(165), pp. 59-78.

Feinerman, E., I. Finkelshtain and I. Kan (2004) "On a Political Solution to the NIMBY Conflict", American Economic Review, 94(1), pp. 369-381.

Flatters, F., V. Henderson and P. Mieszkowski (1974) "Public Goods, Efficiency, and Regional Fiscal Equalization”, Journal of Public Economics, 3(2), pp. 99-112.

Frey, B., F. Oberholzer-Gee and R. Eichenberger (1996) "The Old Lady Visits Your Backyard: A Tale of Morals and Markets", Journal of Political Economy, 104(6), pp. $1297-1313$.

Harris, J. and M. Todaro (1970) "Migration, Unemployment and Development: A 
Two-sector Analysis", American Economic Review, 60(1), pp. 126-142.

Levinson, A. (1999) "NIMBY Taxes Matter: The Case of State Hazardous Waste Disposal Taxes", Journal of Public Economics, 74(1), pp. 31-51.

Markusen, J., E. Morey and N. Olewiler (1995) "Competition in Regional Environmental Policies When Plant Locations are Endogenous", Journal of Public Economics, 56(1), pp. 55-77.

Nakagome, M. (1989) "Urban Unemployment and the Spacial Structure of Labor Markets: An Examination of the Todaro Paradox in a Spacial Context", Journal of Regional Science, 29(2), pp. 161-170.

Ortega, J. (2000) "Pareto-improving Immigration in an Economy with Equilibrium Unemployment”, Economic Journal, 110(460), pp. 92-112.

Raimandos, P. (1993) “On the Todaro Paradox”, Economics Letters, 42(2-3), pp. 261-267.

Sato, Y. (2004) "Migration, Frictional Unemployment, and Welfare-improving Labor Policies", Journal of Regional Science, 44(4), pp. 773-793.

Saveyn, B. (2012) “On NIMBY and Commuting”, International Tax and Public Finance, 20(2), pp. 293-311.

Wildasin, D. (1986) Urban Public Finance, Harwood: Chur, Switzerland.

Zenou, Y. (2011) "Rural-urban Migration and Unemployment: Theory and Policy Implications", Journal of Regional Science, 51(1), pp. 65-82. 